To Maega | Jurnal Pengabdian Masyarakat

Agustus-2021, Vol. 4, No. 2, hal, 242-254

$\operatorname{ISSN}(P): 2622-6332 ; \operatorname{ISSN}(E): 2622-6340$

http://www.ojs.unanda.ac.id/index.php/tomaega

\title{
Promosi Kinerja Guru Sekolah Dasar Islam Ummu Aiman Lawang melalui Penggunaan Supervisi Klinis
}

\section{Tutut Chusniyah ${ }^{1 *}$, Lufiana Harnany Utami ${ }^{2}$, Mohammad Bisri ${ }^{1}$, Gebi Angelina Zahra ${ }^{1}$, Agung Minto Wahyu ${ }^{1}$, Muhammad Subkhan ${ }^{3}$}

\author{
1 Jurusan Psikologi, Fakultas Pendidikan Psikologi, Universitas Negeri Malang \\ 2 Jurusan Psikologi, Fakultas Psikologi dan Kesehatan, UIN Sunan Ampel Surabaya \\ ${ }^{3}$ Wakil Kepala Sekolah, SD Ummu Aiman, Lawang \\ *Correspondent Email: tutut.chusniyah.fppsi@um.ac.id
}

\section{Article History:}

Received: 06-07-2021; Received in Revised: 19-07-2021; Accepted: 04-08-2021

DOI: http://dx.doi.org/10.35914/tomaega.v4i2.785

\begin{abstract}
Abstrak
Kualitas pengajaran dan instruksi sangat diperlukan bagi keberhasilan pembelajaran di sekolah. Supervisi di sekolah bertujuan untuk meningkatkan kinerja pengajaran dan instruksi guru. Supervisi sebagai tulang punggung yang menentukan efektivitas sebuah sekolah. Supervisi yang baik melibatkan kegiatan bantuan untuk guru secara langsung dan menginformasikan tentang apa yang harus dilakukan atau telah dilakukan. Supervisi belajar-mengajar di kelas berusaha membantu guru untuk mengajar secara efektif belum tercapai. Metode yang digunakan dalam kegiatan supervisi klinis ini yaitu 1) konferensi perencanaan; 2) observasi kelas; 3) konferensi umpan balik; 4) perencanaan evaluasi. Hasil kegiatan menunjukkan bahwa 1) konferensi perencanaan berhasil memberikan penjelasan kepada pihak sekolah dan guru terkait konsep kegiatan yang akan dilakukan; 2) observasi kelas dilakukan selama aktivitas mengajar yang meliputi pembukaan, main activity, manajemen kelas, dan aktivitas lainnya; 3) konferensi umpan baik dapat memberikan masukan bagi guru terkait kekurangan atau kelemahan yang perlu diperbaiki dalam proses mengajarnya; 4) rancangan evaluasi dapat memformulasi rancangan program khusus untuk guru berdasarkan hasil konferensi umpan balik. Dengan demikian, dapat disimpulkan bahwa adanya supervisi klinis sangat berguna dalam mempromosikan kinerja guru.
\end{abstract}

Kata Kunci: Kinerja Guru, Guru Sekolah Dasar, Supervisi Klinis

\section{Abstract}

The quality of teaching and instruction is indispensable for successful learning in schools. Supervision in schools aims to improve teaching performance and teacher instruction. Supervision is the backbone that determines the effectiveness of a school. Good supervision involves directly assisting teachers and informing them of what needs to be done or has been done. Supervision of teaching and learning in the classroom trying to help teachers to teach effectively has not been achieved. The methods used in this clinical supervision activity are 1) planning conference; 2) class observation; 3) feedback conference; 4) evaluation planning. The results of the activities showed that 1) the planning conference was successful in providing explanations to the school and 
teachers regarding the concept of the activities to be carried out; 2) class observations are carried out during teaching activities which include opening, main activity, class management, and other activities; 3) feedback conferences can provide input for teachers regarding deficiencies or weaknesses that need to be improved in the teaching process; 4) the evaluation design can formulate a special program design for teachers based on the results of the feedback conference. Thus, it can be concluded that clinical supervision is very useful in promoting teacher performance.

Key Word: Clinical Supervision, Elementary School Teacher, Teacher Performance.

\section{Pendahuluan}

Pendidikan bertujuan untuk membangun martabat dan peradaban manusia. Melalui pendidikan setiap individu berprosesi menjadi manusia yang berkualitas secara mental, spiritual maupun kognitif. Namun, rendahnya mutu pendidikan menjadi hambatan bagi individu untuk meningkatkan kualitas dirinya dan menghambat kesuksesan bangsa Indonesia dalam percaturan abad 21. Pendidikan bermutu adalah pendidikan yang mampu mengembangkan potensi-potensi positif yang terpendam dalam diri siswa didik (Widodo, 2015).

Salah satu aspek terpenting dalam pencapaian mutu dalam proses pendidikan adalah Guru. Kualitas pengajaran dan instruksi yang dilakukan oleh guru merupakan kondisi yang diperlukan bagi keberhasilan pembelajaran di sekolah dan lembaga pendidikan. Pengawasan/ supervisi di sekolah dimaksudkan untuk meningkatkan kinerja pengajaran dan instruksi guru. Glickman dkk. (2004), menempatkan supervisi sebagai tulang punggung yang menentukan efektivitas sebuah sekolah. Supervisi yang baik melibatkan kegiatan bantuan langsung untuk guru dan menginformasikan tentang apa yang harus dilakukan atau telah dilakukan sehingga tidak hanya menemukan kesalahan guru dalam mengajar.

Sahertian (2010) menggambarkan supervisi sebagai visi yang dikembangkan secara kolaboratif dan diwujudkan bersama sehingga terbentuk kesepakatan dalam menetapkan struktur kegiatan yang akan dilakukan. Supervisor/pengawas sendiri merupakan orang yang membantu, membimbing, mengarahkan, dan mengawasi orang-orang yang dikelola (Langton dkk., 2011). Supervisi membentuk hubungan superviror dan supervisee yang fokus pada strategi menyeluruh bagi pencapaian tujuan organisasi dan individu. Kapasitas guru dibangun dalam sistem pengawasan yang mendorong guru untuk mencapai potensi penuh mereka, dan membantu mengembangkan hubungan interpersonal dan budaya organisasi yang produktif (Dessler dkk., 2015).

Hasil studi pendahuluan dengan kepala SD Ummu Aiman menyatakan bahwa salah satu masalah utama guru adalah kemampuan untuk menciptakan inovasi dan kreativitas dalam pembelajaran yang dapat membuat siswa nyaman dan antusias dalam mengikuti pembelajaran. Hal itu terjadi karena siswa tidak merasa bosan dalam mengikuti pembelajaran yang inovatif dan tidak monoton. Didukung hasil penelitian Wahyu, dkk. (2021) yang memaparkan bahwa kemampuan guru dalam menempatkan diri sesuai dengan kondisi siswa dan kelas license (https://creativecommons.org/licenses/by-sa/4.0/). 
merupakan hal yang penting dilakukan. Oleh karena itu, perlu dilakukan upaya intervensi yang dapat mengatasi permasalahan tersebut. Intervensi tersebut dapat dilakukan dengan menggunakan supervisi klinis.

Supervisi klinis adalah pertemuan antara supervisor dan guru yang membahas terkait pengajaran di dalam kelas guna perbaikan pembelajaran dan pengembangan profesi dengan cara kolegial antara supervisor dan guru (Masaong, 2013). Melalui supervisi klinis yang efektif, guru dapat meningkatkan kinerja mengajar dan tingkat pengetahuan mengajar di dalam maupun di luar kelas. Peran supervisor adalah menjadi fasilitator yang bertanggung jawab untuk menciptakan lingkungan yang mendorong refleksi, eksplorasi, dan perubahan (Hasanah, 2012). Supervisi klinis difokuskan pada kualitas pengajaran, dan evaluasi terhadap guru dapat menjadi katalisator dalam meningkatkan pengajaran dan kinerja guru sekolah (Thomas, 2008), sehingga peran supervisor seperti cermin yang memungkinkan supervisee untuk memeriksa kembali praktik mengajar mereka tanpa nada evaluatif atau menghakimi (Nurbaya, 2017).

Menurut Novianti (2015), kepala sekolah lebih banyak mengabdikan waktunya pada aspek administrasi dan kurang memberikan perhatian pada supervisi klinis. Padahal supervisi klinis yang dilaksanakan di sekolah membantu dalam meningkatkan kualitas pengajaran guru sehingga praktik mengajar mereka lebih efektif (Holland dan Adams, 2002). Baharom (2002) menemukan bahwa supervisi belajar-mengajar di kelas yang berusaha membantu guru untuk mengajar secara efektif belum tercapai, karena sikap guru yang tidak efisien dan ketidaksiapan kepala sekolah untuk melakukan supervisi klinis sehingga supervisi klinis belum dilakukan secara memadai (Haliza, 2005). Selanjutnya Baharom menemukan bahwa sekitar $12,03 \%$ guru sekolah dasar tidak setuju dengan pelaksanaan supervisi klinis, karena guru beranggapan bahwa pelaksanaan supervisi klinis di sekolah semata-mata untuk mencari kelemahan guru. Pada kenyataannya, di New York (Amerika Serikat) saja, seorang guru yang mengajar lima periode sehari (900 periode setahun) diamati atau diawasi hanya sekali dan 99\% dari pengajaran guru tidak diawasi dengan baik (Marshall, 2005).

Meskipun model supervisi klinis/MSK (clinical supervision model/CSM) telah diterapkan di Amerika Serikat sejak tahun 1960-an (Pajak, 2002), namun model ini merupakan konsep yang masih membutuhkan lebih banyak persiapan guru dan kebutuhan guru untuk mendapatkan supervisi/pengawasan klinis yang efektif bagi guru. Meskipun digunakan secara global dan luas dalam pendidikan, ada kelangkaan pelaksanaan dan efektivitas pengalaman supervisi klinis di sekolah dasar. Oleh karena itu, supervisi klinis untuk guru-guru SD ini perlu untuk dilakukukan. Asumsinya adalah bahwa tanpa bimbingan dan pendampingan, guru tidak dapat mengubah atau meningkatkan kinerjanya (Pawlas dan Oliva, 2007). Hasil penelitian menunjukkan bahwa 82,5\% guru setuju bahwa 
supervisi klinis harus difokuskan pada teknik pengajaran, gaya bertanya, induksi dan komunikasi dua arah antara guru dan siswa (Maunah, 2016).

Inti supervisi klinis adalah proses dimana kinerja pengajaran secara sistematis diamati, dianalisis, dan dievaluasi (Gaies dan Bowers, 2010). Proses siklus dilakukan secara berkala bukan hanya observasi kelas yang dilakukan sekali atau dua kali setahun. Richards dan Schmidt (2010) menyajikan siklus supervisi yang meliputi: 1) Sebuah konferensi perencanaan, di mana guru mendiskusikan tujuan, metodologi, masalah, dll. dengan supervisor dan memutuskan apa yang harus diamati dan jenis informasi tentang pelajaran yang harus dikumpulkan, 2) Observasi kelas, di mana supervisor mengamati guru di kelasnya, dan 3) Konferensi umpan balik, di mana guru dan supervisor meninjau data yang telah dikumpulkan, mendiskusikan keefektifan pelajaran, dan memutuskan strategi perbaikan. Fase observasi dan konferensi menjadi cara yang sangat penting bagi guru dan supervisor untuk merefleksikan dan menyempurnakan praktik pengajaran. Ketiga tahap ini membuka jalan untuk kolaborasi yang kuat dan pertukaran ide yang cermat antara supervisor dan guru, karena keduanya menerima umpan balik yang membangun dari perspektif yang berbeda.

\section{Metode}

Guna menunjang keberhasilan pelaksanaan supervisi klinis terhadap guru dan peningkatan kemampuan guru perlu dilaksanakan tiga tahap supervisi guna rmemaksimalkan keberhasilan kinerja pengajaran dan instruksi guru. Kegiatan dilakukan selama tiga hari pada tanggal 8-10 Februari 2021yang bertempat di SD Ummu Aiman. Upaya untuk memaksimalkan hasil dari supervisi klinis ini dilaksanakan melalui beberapa metode sebagai berikut:

\section{Konferensi perencanaan}

Pada tahap ini guru mendiskusikan dengan supervisor terkait tujuan, metodologi, dan masalah dalam pembelajaran, serta memutuskan jenis informasi apa yang akan diamati dan dikumpulkan. Konferensi perencanaan sangat menentukan keberhasilan dari program pelaksanaan karena berkaitan dengan pengetahuan terhadap mekanisme dan prosedur selama kegiatan.

\section{Observasi kelas}

Observasi merupakan proses penggalian data yang dilakukan langsung dengan cara melakukan pengamatan mendetail pada objek observasi dan lingkungannya dalam kancah riset (Creswell, 2014). Dalam kegiatan ini, supervisor mengamati guru yang sedang mengajar di dalam kelas.

\section{Konferensi umpan balik}

Konferensi umpan balik dilakukan supervisor dengan meninjau data yang telah dikumpulkan, mendiskusikan keefektifan pelajaran, dan memutuskan strategi perbaikan. Kemudian supervisor menyampaikan umpan balik dari hasil 
observasi sebelumnya kepada guru. Guru diminta untuk menampung hasil umpan balik yang diberikan oleh supervisor.

\section{Rancangan evaluasi}

Dalam pelaksanaan program pengabdian dalam bentuk pelatihan ini terdapat 3 kriteria yang akan menjadi tolak ukur dasar pencapaian dari kegiatan pelatihan.

Tolak ukur keberhasilan dari pelaksanaan kegiatan adalah dengan melaksanakan kegiatan sesuai dengan waktu dan jumlah pertemuan yang telah ditentukan sehingga sinergitas yang baik antara pelaksana dengan peserta.

Tolak ukur keberhasilan dari pihak peserta antara lain adalah peserta mampu mengimplementasikan saran dan masukan dari kegiatan supervisi klinis ini untuk kegiatan mengajar.

Tolak ukur keberhasilan dari pihak pelaksana adalah mampu memberikan penjelasan serta bantuan yang dapat membantu peserta yang menagalami kesulitan dalam melakukan praktik membuat produk. Selain itu, keberhasilan tim pelaksana juga dapat diukur dari pelayanan yang baik dalam melakukan komunikasi pada saat pelaksanaan kegiatan serta kesesuaian jumlah kehadiran tim pelaksana yang sesuai dengan jumlah pertemuan yang telah ditentukan.

\section{Hasil dan Pembahasan}

Gambaran umum terkait dengan pelaksanaan supervisis klinis pada pelaksanaan pembelajaran di kelas berbasis teknologi di SD Ummu Aiman diawali dengan melaksanakan analisis kebutuhan dari sekolah mitra, koordinasi rencana kegiatan, analisis materi yang akan digunakan, pelaksanaan kegiatan, dan evaluasi. Program supervisi yang dilakukan di SD Ummu Aiman, Lawang, Malang dengan target peserta yakni kepala sekolah dan guru. Pada tahap awal, kegiatan melibatkan ketua dan dua anggota tim yang merupakan alumni Prodi S3 Psikologi Pendidikan dan S1 Psikologi, Fakultas Pendidikan Psikologi, Universitas Negeri Malang. Selain itu juga dibantu oleh satu tenaga pembantu lapangan. Supervisi klinis yang dilakukan di SD Ummu Aiman adalah upaya pembinaan guru untuk meningkatkan kemampuan mereka dalam menjalankan profesinya sebagai pengajar dan pendidik.

Kegiatan pertama diawali dengan konferensi perencanaan terhadap supervisi klinis yang akan dilakukan. Konferensi perencanaan dilakukan untuk membahas metode yang digunakan pada pelaksanaan supervisi klinis, mengenalkan kelompok pelaksana dalam supervisi klinis, dan menyiapkan peralatan yang digunakan dalam menunjang kegiatan supervisi klinis.

Pembinaan dalam supervisi klinis meliputi pendampingan guru dalam merencanakan pembelajarannya, mengoptimalkan potensi yang dimiliki guru, memotivasi guru untuk mencintai profesi yang dipilihnya, serta mengingatkan guru untuk terus belajar dan menambah ilmunya setiap saat. Apapun yang dilakukan guru tentunya adalah upaya untuk memberikan pelayanan pendidikan CTo Maega / Jurnal Pengabdian Masyarakat. This is an open access article under the CC BY-SA 4.0 license (https://creativecommons.org/licenses/by-sa/4.0/). 
terbaik bagi para siswa sehingga semua sikap dan perilaku guru pun akan menjadi sorotan untuk bahan supervisi. Kemampuan dalam penyampaian konsep pelajaran perlu diimbangi dengan kreativitas mendesain kegiatan pembelajaran yang membuat siswa mudah mempelajari apa yang harus dipahami. Ada tiga topik utama yang biasanya menjadi bahan supervisi guru yaitu Rencana Pelaksanaan Pembelajaran (RPP), manajemen kelas, dan evaluasi (Kristiawan dkk., 2019; Sabandi, 2013).

Berikutnya memasuki kegiatan utama yaitu observasi kelas. Observasi kelas dilakukan selama seminggu terhadap 20 orang guru SD UA, dengan rincian 5 orang guru IPA, 4 orang guru matematika, 3 orang guru agama, 2 orang guru bahasa indonesia, 2 orang guru bahasa jawa, dan masing-masing 1 orang guru IPS, TIK, penjaskes, dan bahasa arab. Durasi observasi beragam sesuai dengan lama mengajar setiap guru yang menjadi observee.

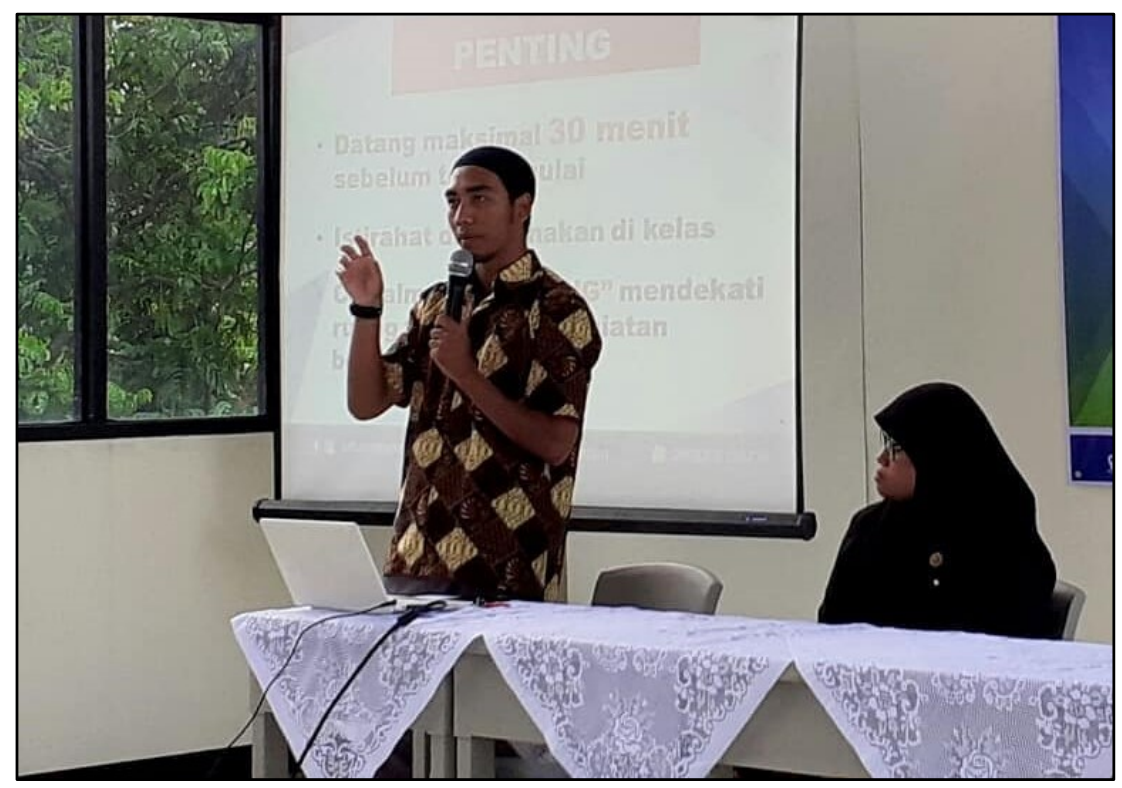

Gambar 1. Proses Observasi pada Guru

Observasi kelas dilakukan satu-persatu pada guru pengajar yang meliputi 1) aktivitas pembukaan, mengamati mendalam pada aktivitas selama awal guru mengajar hingga sebelum memasuki tahap inti dalam mengajarkan suatu materi; 2) main activity, mengamati mendalam pada aktivitas inti guru dalam mengajar, menugaskan, dan mempraktikkan suatu materi yang menjadi tujuan pembelajaran pertemuan tersebut; 3) manajemen kelas, mengamati mendalam pada aktivitas guru dalam membawakan dan mengendalikan segala sesuatu yang ada di dalam kelas selama mengajar; 4) aktivitas lain, mengamati mendalam hal-hal lain yang menjadi temuan menarik di luar pembukaan, main activity, dan manajemen kelas.

Berikut adalah salah satu hasil observasi kelas pada beberapa guru telah dijabarkan dalam tabel berikut. 
Tabel 1. Hasil Observasi

Observee $=$ Ibu YH (Guru Bahasa Indonesia/Kelas II)

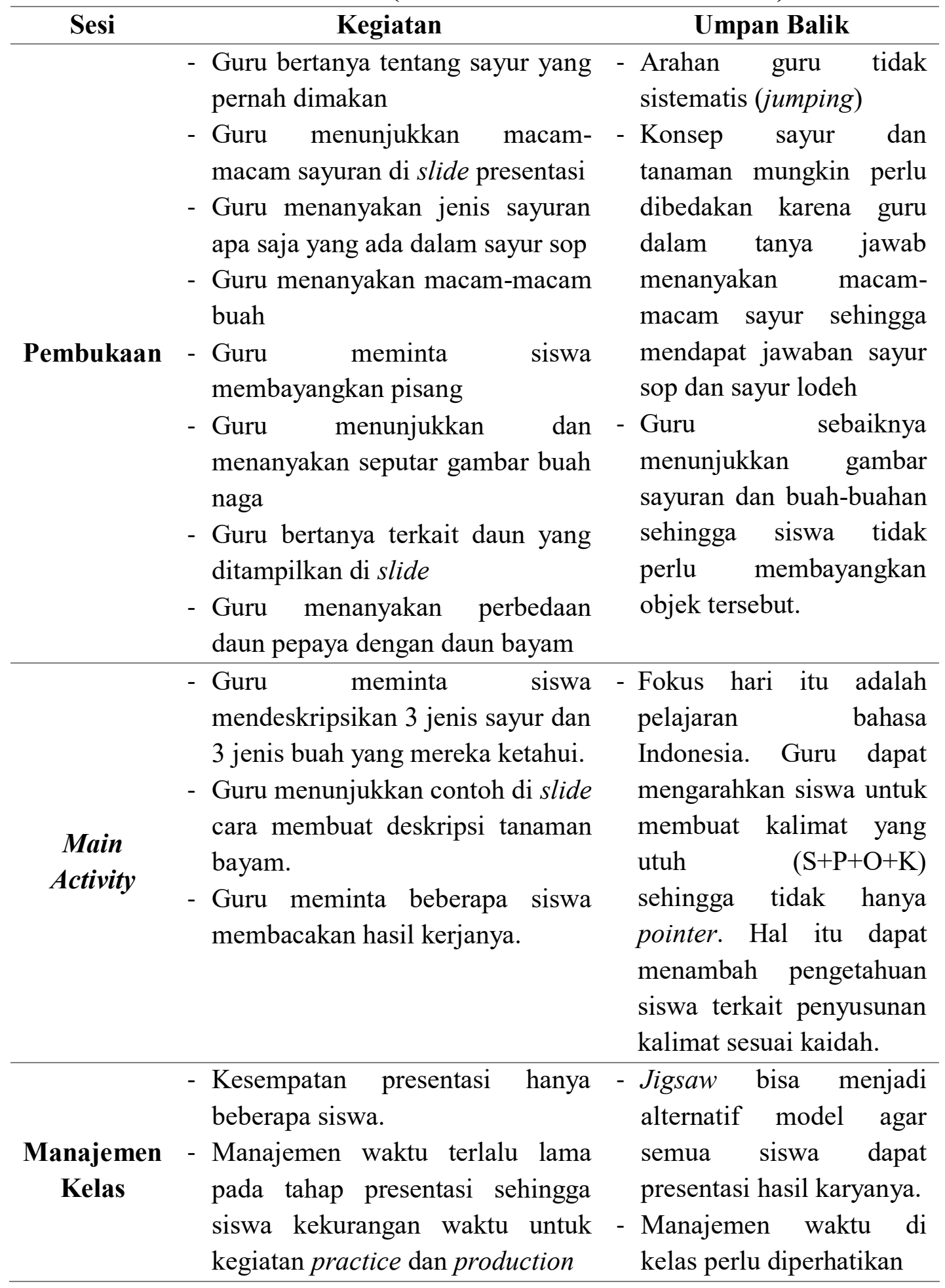

Berikutnya adalah konferensi umpan balik untuk menggambarkan skenario pembelajaran yang dilakukan guru pada jadwal supervisi yang telah ditentukan. 
Segala sesuatu yang dilakukan guru telah didokumentasikan dan didiskusikan hasilnya bersama yang bersangkutan. Beberapa kondisi yang ditemukan pada mayoritas guru kemudian ditarik menjadi temuan umum yang nantinya perlu menjadi perhatian. Hal serupa juga telah dilakukan Huda dkk (2020); Junaid dan Baharuddin (2020) yang hasilnya terbukti efektif. Rangkaian kegiatan supervisi klinis di SD Ummu Aiman telah terangkum dalam tabel berikut.

Tabel 2. Rangkaian Kegatan Supervisi Klinis

\begin{tabular}{llcc}
\hline \multicolumn{2}{c}{ Uraian Kegiatan } & Keterangan \\
\hline Konferensi Perencanaan & & \\
\cline { 1 - 2 } & - & Penjelasan metode pelaksanaan & Kegiatan \\
& - Perkenalan kelompok pelaksana & $100 \%$ \\
Tujuan & - & Persiapan peralatan yang akan digunakan & Tercapai \\
& pengenalkan metode pelaksanaan program & \\
& Melakukan persiapan peralatan yang digunakan & \\
& dalam pelaksanaan program pengabdian. & \\
\hline
\end{tabular}

Observasi Kelas

Aktivitas - Observasi selama guru melakukan pembukaan.

- Observasi selama main activity (practice dan production).

- Observasi dalam manajemen kelas.

Kegiatan

- Observasi selama guru melakukan aktivitas lainnya. $\quad 100 \%$

Tujuan - Memperoleh gambaran aktivitas guru selama Tercapai melakukan pembukaan, main activity, dan manajemen kelas selama mengajar.

- Mendapatkan hasil observasi yang dapat digunakan sebagai penunjang dalam merumuskan ide/saran untuk guru ketika mengajar di kelas

\begin{tabular}{|c|c|c|}
\hline \multicolumn{2}{|c|}{ Konferensi Umpan Balik } & \multirow[b]{2}{*}{$\begin{array}{c}\text { Kegiatan } \\
100 \% \\
\text { Tercapai }\end{array}$} \\
\hline Aktivitas & 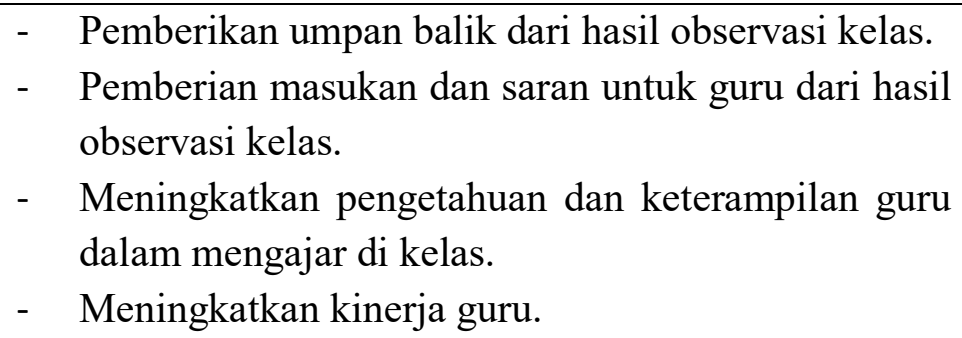 & \\
\hline \multicolumn{2}{|c|}{ Rancangan Evaluasi } & \multirow{3}{*}{$\begin{array}{c}\text { Kegiatan } \\
100 \% \\
\text { Tercapai }\end{array}$} \\
\hline Aktivitas & $\begin{array}{l}\text { - Perancangan evaluasi dalam guru mengajar dari } \\
\text { hasil umpan balik }\end{array}$ & \\
\hline Tujuan & $\begin{array}{l}\text { - Memformulasikan rancangan program khusus untuk } \\
\text { guru agar dapat meningkatkan kemampuannya }\end{array}$ & \\
\hline
\end{tabular}

CTo Maega / Jurnal Pengabdian Masyarakat. This is an open access article under the CC BY-SA 4.0 license (https://creativecommons.org/licenses/by-sa/4.0/). 
dalam mengajar

Temuan dari hasil supervisi klinis diantaranya yaitu guru hanya mengunduh Rencana Pelaksanaan Pembelajaran (RPP) dari internet sehingga mereka perlu mendapatkan pelatihan cara membuat RPP, sebab persiapan yang dilakukan guru untuk pembelajaran akan tergambarkan dari Rencana Pelaksanaan Pembelajaran (RPP). Oleh karena itu, pembuatan RPP merupakan hal yang sangat penting. Dalam proses pembuatannya, kegiatan yang memberikan siswa pengalaman dalam proses belajar sebaiknya menjadi perhatian dalam desain kegiatan RPP. Tahapan penyampaian materi pun harus dibuat sistematis mengikuti kondisi perkembangan siswa pada setiap kelas sehingga materi yang diterima tidak menjadi hal yang menakutkan bagi siswa.

Dalam upaya merencanakan desain kegiatan yang kreatif tentunya guru perlu banyak ide dan itu bisa difasilitasi dengan pertemuan guru-guru per level kelas. Diharapkan semua guru akan berkolaborasi mengumpulkan ide mereka untuk nantinya menjadi desain pembelajaran yang akan dituangkan dalam RPP. Hasil pelatihan RPP yang dilakukan Nadia dkk. (2020) menunjukkan bahwa para guru mendapat banyak pengetahuan baru terkait metode pembelajaran, sekaligus praktik serta sharing rencana pembelajaran yang bisa mereka adopsi atau adaptasi di kelas masing-masing.

Temuan lain yaitu pembelajaran masih bersifat teacher-centered dimana guru masih lebih mendominasi selama jam pelajaran. Maka dari itu, teknik pengajaran yang lebih variatif dibutuhkan oleh guru agar mengarah ke studentcentered. Di samping itu, beberapa guru juga mengeluhkan beban materi yang harus disampaikan dan cara membuat siswa menguasai keseluruhan materi tersebut. Sistem tematik dapat menjadi solusi agar lintas pelajaran dapat saling mendukung.

Konferensi umpan balik dalam hal manajemen kelas yang terkait manajemen waktu perlu ditingkatkan dengan pembagian sesi 1) pembukaan 10-15 menit; 2) main activity 30-40 menit; 3) closing 10 menit). Di samping itu, manajemen aktivitas untuk siswa juga perlu menjadi perhatian agar pada pembukaan ketika guru menjelaskan konsep atau rencana kegiatan pengajaran pada hari itu dilakukan dalam kondisi siswa tenang dan penuh perhatian. Karena concentration span siswa hanya bisa bertahan selama 10-15 menit sehingga guru harus mampu memanfaatkan waktu yang singkat tersebut untuk kegiatan pembelajaran. Ketika memasuki main activity, guru diharapkan membuat siswa bekerja dengan desain kegiatan yang dapat memberikan pengalaman belajar (do something) bermakna. Ketika closing, guru dapat mengajak siswa menyimpulkan apa yang telah dipelajari dan melakukan self-reflection (aktivitas yang sudah lakukan, perasaan selama mengikuti kelas). 
Kemampuan manajemen kelas tersebut menajdi salah satu kunci yang harus dimiliki guru dalam proses pembelajaran karena dengan manajemen kelas yang baik guru dapat menjalankan apa yang telah direncanakan. Suryana (2012) menjelaskan bahwa karakter siswa memang menjadi pertimbangan karena tidak jarang apa yang telah direncanakan harus berubah karena adanya hal-hal di luar dugaan. Dalam mengelola kelas guru terkadang masih perlu masukan dari supervisi yang dilakukan kepala sekolah agar hal-hal yang mungkin tidak terlihat oleh guru di kelas tetapi terlihat oleh kepala sekolah. Pendampingan terhadap guru untuk terus meningkatkan kemampuannya dalam mengelola kelas harus terus dilakukan dengan konsisten setiap hari. Pembentukan karakter siswa juga bersandar pada manajemen kelas yang baik dari seorang guru sehingga siswa mendapatkan perlakukan yang sama setiap hari.

Salabi (2016) menjelaskan bahwa fungsi manajemen kelas meliputi 1) fungsi pengembangan, yaitu fungsi manajemen kelas dimana guru secara proaktif merencanakan dan melaksanakan seperangkat kegiatan pembelajaran yang berlangsung dengan lancar, tertib, efektif, dan produktif; (2) fungsi pengendalian, seperangkat kegiatan guru yang bermakna menjaga, membina, mem-pertahankan, dan mengendalikan kondisi kelas agar tetap efektif dan produktif bagi kegiatan pembelajaran; dan (3) fungsi penyembuhan, mengembalikan kondisi kelas yang telah terkontaminasi oleh gangguan ke dalam keadaan semula seperti sebelum terjadinya gangguan.

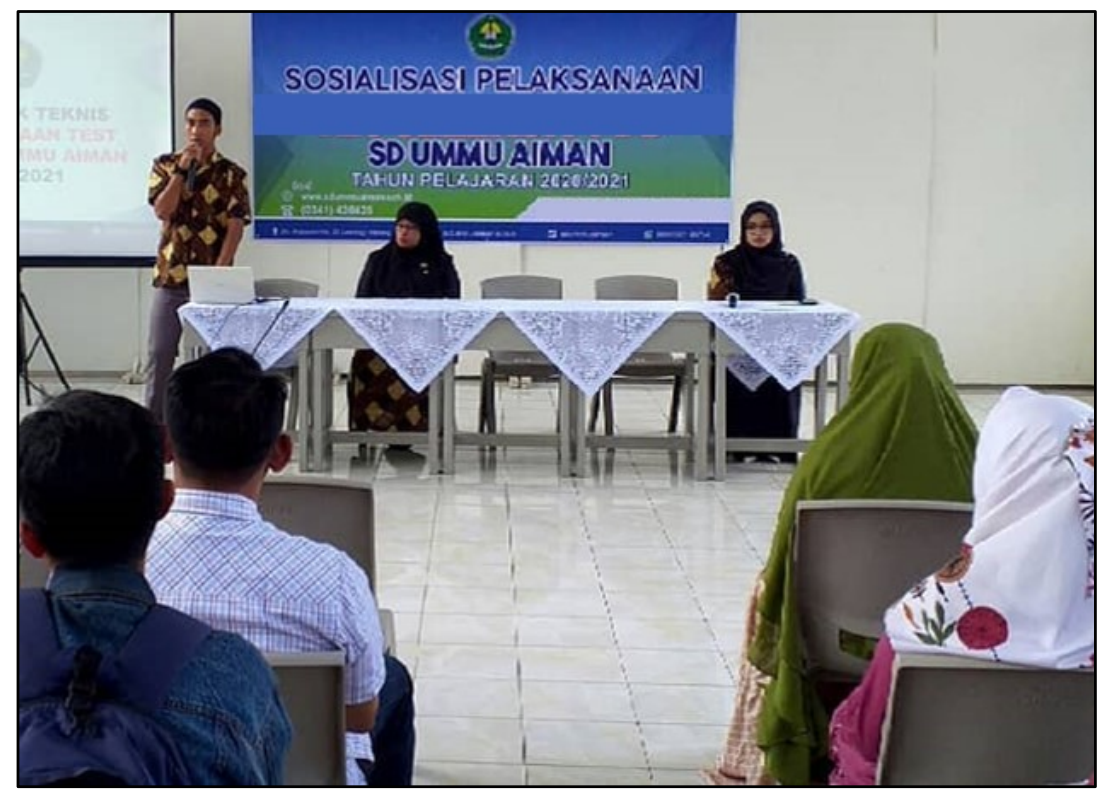

Gambar 2. Proses Pelaksanaan Konferensi Umpan Balik

Aspek lain yang dapat menjadi perhatian guru dalam mengajar di kelas adalah 1) manajemen fisik kelas agar lebih rapi dan bersih untuk lingkungan belajar; 2) manajemen siswa dengan sikap guru yang tegas (bukan galak) dan 
tidak menjadikan kepala sekolah atau pihak lain sebagai ancaman untuk membuat siswa patuh dan kondusif. Guru juga dapat menggunakan konsep display kelas dalam bentuk riil maupun digital yang bisa digunakan untuk media pembelajaran sehingga membantu siswa mengingat hal yang dipelajari, serta meningkatkan motivasi siswa agar dapat memajang hasil karyanya.

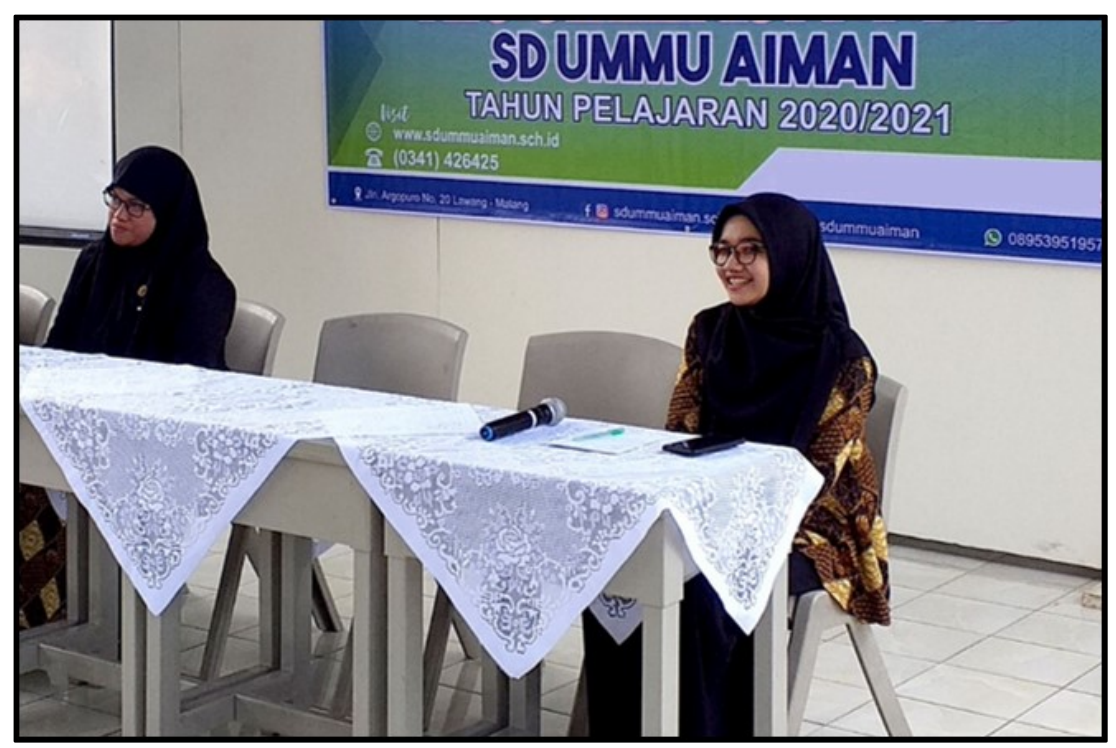

Gambar 3. Proses Perancangan Evaluasi

Hal lain yang juga perlu menjadi perhatian adalah kondisi guru yang mengajar lintas kelas membuat guru kelas tidak dapat fokus dengan pengembangan ide pembelajaran di kelasnya. Sistem guru kelas mungkin bisa menjadi solusi sehingga pertemuan untuk mendiskusikan ide-ide pembelajaran per kelas pun bisa dilakukan dengan lebih intensif (sampai micro teaching).

\section{Kesimpulan dan Saran}

Berdasarkan hasil pemaparan sebelumnya, dapat disimpulkan bahwa kegiatan supervisi klinis dilakukan dengan menggunakan empat metode, yaitu 1) konferensi perencanaan, dilakukan untuk membahas metode yang digunakan pada pelaksanaan supervisi klinis; 2) observasi kelas, observasi kelas dilakukan selama seminggu terhadap 20 orang guru SD UA yang meliputi aktivitas pembukaan, main activity, manajemen kelas, dan aktivitas lainnya; 3) konferensi umpan balik, untuk memberi informasi pada guru tentang kelemahan dan kelebihannya mengenai teknik, metode, pendekatan dan alat peraga yang digunakan.; 4) rancangan evaluasi, dilakukan untuk menemukan program-program untuk guru yang dapat mengurangi kelemahannya dalam mengajar. Hasil kegiatan menunjukkan bahwa guru menjadi mampu menyadari kelemahan dan 
kekurangannya dalam mengajar sehingga ke depan akan berusaha untuk memperbaikinya.

Saran untuk guru dapat menerima dan mempertimbangkan umpan balik dari hasil supervisi klinis ini. Harapannya adalah agar kinerja guru dalam mengajar menjadi lebih baik. Di sisi lain, sekolah diharapkan dapat memfasilitasi segala kebutuhan program untuk guru dalam meningkatkan kemampuan mengajarnya.

Saran untuk pengabdi selanjutnya adalah agar melakukan pelatihan untuk kepala sekolah dan wakilnya tentang supervisi klinis, dan pendampingan supervisi oleh kepala sekolah atau wakil kepala sekolah dalam program supervisi klinis yang berkelanjutan.

\section{Ucapan Terimakasih}

Terima kasih kepada 1) Universitas Negeri Malang yang telah memberikan pendanaan sepenuhnya untuk melaksanakan pengabdian masyarakat di SD Ummu Aiman Lawang; 2) SD Ummu Aiman Lawang yang mengizinkan untuk dilaksanakan pengabdian masyarakat dalam bentuk pemberian supervisi klinis.

\section{Daftar Pustaka}

Baharom, M. (2002). Persepsi Guru-Guru terhadap Kepemimpinan Pengajaran dalam Celik Computer di Sekolah-Sekolah Negeri Johor. Tesis Ijazah Doktor. Selangor: Universiti Kebangsaan Malaysia.

Creswell, J. W. (2014). Research Design: Qualitative, Quantitative and Mixed Methods Approaches (4th ed.). Sage Publications.

Dessler, G., Munro, C. R., \& Cole, N. D. (2015). Management of Human Resources. Pearson.

Gaies, S., \& Bowers, R. (2010). Clinical Supervision of Language Teaching: the Supervisor as Trainer and Educator. In A Course Pack on Teacher Development in ELT. KU.

Glickman, C. D., Gordon, S. P., \& Ross-Gordon, J. M. (2004). Supervision and Instructional Leadership: Adevelopmental Approach (6th ed.). Pearson Education Inc.

Haliza, H. (2005). Amalan dan Keberkesanan Penyeliaan Pengajaran Di Sekolah Menengah Luar Bandar Daerah Muar. Tesis Sarjana. Kuala Lumpur: Universiti Teknologi Malaysia.

Hasanah, A. (2012). Pengembangan Profesi Guru. Pustaka Setia.

Holland, P. E., \& Adams, P. (2002). Through the Horns of Dilemma between Instructional Supervision and the Summative Evaluation of Teaching. Journal of Educational Leadership, 5(3), 227-247.

Huda, N., Mardiana, N., \& Imayah, I. (2020). Strategi Pembelajaran bagi Guru di Lembaga Pendidikan Islam Anak Sholeh Pepelegi, Sidoarjo. To Maega: license (https://creativecommons.org/licenses/by-sa/4.0/). 
[ 254 ] Tutut Chusniyah, dkk / To Maega : Jurnal Pengabdian Masyarakat, Vol. 4; No. 2; Agustus, 2021

Jurnal Pengabdian Masyarakat, 3(2), 111-121.

Junaid, R., \& Baharuddin, M. R. (2020). Peningkatan Kompetensi Pedagogik Guru melalui PKM Lesson Study. To Maega: Jurnal Pengabdian Masyarakat, 3(2), 122-129.

Kristiawan, M., Yuniarsih, Y., Fitria, H., \& Refika, N. (2019). Supervisi Pendidikan. Alfabeta.

Langton, N., Robbins, S. P., \& Judge, T. A. (2011). Fundamentals of Organizational Behaviour. Pearson Prentice Hall.

Marshall, K. (2005). It's Time to Rethink Teacher Supervision and Evaluation. Phi Delta Kappan, 87(10), 727-735.

Masaong, A. K. (2013). Supervisi Pembelajaran dan Pengembangan Kapasitas Guru: Memberdayakan Pengawas Sebagai Gurunya Guru. Alfabeta.

Maunah, B. (2016). Pembinaan Guru dengan Pendekatan Supervisi Klinis. Didaktika Religia, 1(2), 1-12.

Nadia, H., Yansyah, \& Murtiningsih, T. (2020). Pelatihan Pembuatan RPP Menggunakan Metode 4 C'S Bagi Guru-Guru MGMP Bahasa Inggris Kalimantan Selatan. Jurnal Pemberdayaan: Publikasi Hasil Pengabdian kepada Masyarakat, 4(3), 339-346.

Novianti, H. (2015). Pelaksanaan Supervisi Akademik Kepala Sekolah dalam Meningkatkan Kinerja Guru. Manajer Pendidikan, 9(2), 350-358.

Nurbaya. (2017). Peranan Supervisor dalam Meningkatkan Profesionalitas Guru di SDN 14 Allu Kabupaten Bantaeng. Skripsi. Makassar: UIN Alauddin Makassar.

Pajak, E. (2002). Clinical Supervision and Psychological Functions: A New Direction for Theory and Practice. Journal of Curriculum and Supervision, 17(3), 189-205.

Pawlas, G. E., \& Oliva, P. F. (2007). Supervision for Today's Schools. Wiley Jossey Bass-Education.

Richards, J. C., \& Schmidt, R. (2010). Longman Dictionary of Language Teaching and Applied Linguistics (4th ed). Longman (Pearson Education).

Sabandi, A. (2013). Supervisi Pendidikan untuk Pengembangan Profesionalitas Guru Berkelanjutan. PEDAGOGI: Jurnal Ilmiah Ilmu Pendidikan, 13(2), 19.

Sahertian, P. A. (2010). Konsep Dasar dan Teknik Supervisi Pendidikan. Rineka Cipta.

Salabi, A. (2016). Konsepsi Manajemen Kelas: Masalah dan Pemecahannya. Jurnal Tarbiyah (Jurnal Ilmiah Kependidikan), 5(2), 69-78.

Suryana, E. (2012). Manajemen Kelas Berkarakteristik Siswa. Jurnal Pendidikan Islam, 1(2), 1-16.

Wahyu, A. M., Pangestu, A., Sulistiyaningsih, R., \& Setiyowati, N. (2021). Intelligence Concept: A Cross-cultural Study of University Students from The Javanese and Madurese in East Java. KARSA: Journal of Social and (C)To Maega / Jurnal Pengabdian Masyarakat. This is an open access article under the CC BY-SA 4.0 license (https://creativecommons.org/licenses/by-sa/4.0/). 
[ 255 ] Tutut Chusniyah, dkk / To Maega : Jurnal Pengabdian Masyarakat, Vol. 4; No. 2; Agustus, 2021

Islamic Culture, 29(1), 1-26.

Widodo, H. (2015). Potret Pendidikan Di Indonesia dan Kesiapannya dalam Menghadapi Masyarakat Ekonomi Asia (MEA). Cendekia, 13(2). 